Case Report

\title{
Posttransplant Tacrolimus-Induced Diabetic Ketoacidosis: Review of the Literature
}

\author{
Zaid Ammari, ${ }^{1}$ Stella C. Pak, ${ }^{1}$ Mohammed Ruzieh $\mathbb{D}^{1},{ }^{1}$ Osama Dasa $\mathbb{D}^{1},{ }^{1}$ Abhinav Tiwari $\mathbb{D},{ }^{1}$ \\ Juan C. Jaume, ${ }^{1,2,3}$ and Maria A. Alfonso-Jaume ${ }^{1,3,4}$ \\ ${ }^{1}$ Department of Medicine, College of Medicine and Life Sciences, University of Toledo, Toledo, OH, USA \\ ${ }^{2}$ Division of Endocrinology, Diabetes and Metabolism, College of Medicine and Life Sciences, University of Toledo, Toledo, OH, USA \\ ${ }^{3}$ Center for Diabetes and Endocrine Research (CeDER), College of Medicine and Life Sciences, University of Toledo, Toledo, OH, USA \\ ${ }^{4}$ Division of Nephrology, College of Medicine and Life Sciences, University of Toledo, Toledo, OH, USA
}

Correspondence should be addressed to Maria A. Alfonso-Jaume; Maria.Alfonso-Jaume@utoledo.edu

Received 10 February 2018; Accepted 2 April 2018; Published 9 May 2018

Academic Editor: John Broom

Copyright (C) 2018 Zaid Ammari et al. This is an open access article distributed under the Creative Commons Attribution License, which permits unrestricted use, distribution, and reproduction in any medium, provided the original work is properly cited.

Diabetic ketoacidosis (DKA) in patients receiving tacrolimus as part of their immunosuppressive regimen is a rarely reported adverse event. We report a patient with autosomal dominant polycystic kidney disease (ADPKD) and no known history of diabetes mellitus who presented with DKA, 3 months after kidney transplantation.

\section{Introduction}

For 2 decades now, kidney allograft survival has been shortening despite an obvious decrease in acute allograft rejection. The possibility of a single agent capable of both outcomes is being considered. Tacrolimus, the most potent calcineurin inhibitor, may be the reason for both. Its popularity is clearly a consequence of the excellent short term outcome. However, as second kidney transplant becomes the norm because of the reduced allograft survival, alternative immunosuppressive regimens ought to be considered.

New-onset diabetes mellitus after transplantation (NODAT) is now a well-established adverse effect of calcineurin inhibitors, mostly tacrolimus. NODAT has been reported to occur in $32 \%$ of patients after solid organ transplantation and may be the most important contributing factor for decreased long-term allograft survival [1]. Immunosuppressant accounts for $74 \%$ of the occurrence of NODAT [2], with a higher incidence in patients receiving tacrolimus than cyclosporine (16.6-33.6\% versus 9.8-26\%) $[3,4]$. Failure to identify and manage glucose homeostasis in a timely manner in these patients lead to a life-threatening complication, DKA.
The case presented here describes an accelerated development of tacrolimus-induced DKA 3 months after kidney transplantation. To our knowledge, only 14 cases of tacrolimus-induced DKA have been reported.

\section{Case Description}

A 44-year-old Caucasian male, with no past medical history of diabetes mellitus, was admitted to the hospital with DKA, three months after receiving a deceased-donor kidney transplant for end stage renal disease (ESRD) secondary to ADPKD. The posttransplant course was unremarkable. Patient's immunosuppressive regimen included tacrolimus $1.5 \mathrm{mg}$ BID, mycophenolate sodium $720 \mathrm{mg}$ BID, and low dose prednisone of $5 \mathrm{mg}$ daily. Patient presented to the emergency department with nausea, polyuria, and abdominal pain. He did not have family history of diabetes mellitus. Physical exam was unremarkable except for mild overweight, body mass index of $27 \mathrm{~kg} / \mathrm{m}^{2}$. Laboratory work-up revealed hyperglycemia, high anion gap metabolic acidosis, significant ketosis with a beta-hydroxybutyrate level of $4.45 \mathrm{mmol} / \mathrm{l}$ (reference range $0.02-0.27 \mathrm{mmol} / \mathrm{l}$ ), ketonuria, and normal lactate levels. Glycated hemoglobin (A1C) was $9.8 \%$ compared 
to $4.8 \%, 30$ days after transplant. Tacrolimus trough level was $13.9 \mathrm{ng} / \mathrm{ml}$. Glutamic acid decarboxylase (GAD-65) autoantibodies were negative. Infectious etiology for hyperglycemia was ruled out.

The patient received intravenous fluids and a bolus of intravenous insulin followed by continuous insulin infusion which was gradually switched to subcutaneous insulin. Daily insulin requirements were approximately 40 units. He was educated about his new diagnosis and discharged on diabetic diet and subcutaneous insulin therapy. Upon followup, tacrolimus dose was adjusted to a lower therapeutic index. Insulin requirements markedly decreased and patient was able to be taken off insulin 9 months after. Glycated hemoglobin (A1C) checked at 9 months was 5.2\%.

\section{Discussion}

Many of the risk factors that predispose nontransplant patients to diabetes mellitus have been identified as risk factors for NODAT. Some risk factors are unique to the transplant population. Immunosuppressive agents that contribute to NODAT include glucocorticoids, calcineurin inhibitors, and mTOR inhibitors. Both cyclosporine and tacrolimus increase the risk of NODAT. Tacrolimus is more diabetogenic than cyclosporine $[3,4]$. Other risk factors are hepatitis $\mathrm{C}$ virus and cytomegalovirus infections, impaired glucose tolerance, perioperative hyperglycemia, HLA matching and donor characteristics, and hypomagnesemia $[1,2,5]$. Interestingly, ADPKD, the cause of ESRD in the present case may confer an increased risk of NODAT [6].

In a study using data from the United States Renal Data System (USRDS), 21,489 patients were enrolled, of whom 4,105 developed NODAT by 3 years after transplant. Diabetes complications developed in $58.3 \%$ of patients. DKA developed in $8.1 \%$ of patients with NODAT [7]. In most of these cases exposure to high dose steroids (steroid-induced diabetes) appears to be a determining factor. Different from many other protocols, our transplant protocol includes a very short (3 days) exposure to high dose steroids.

Including our case, there are 15 cases of tacrolimus associated DKA presentation in organ transplant patients reported in the literature [8-18]. Summary of these cases focused on clinical presentation and management is described in Table 1. Out of the 15 cases, 6 had kidney transplant $[8,10,13,16,17]$, 6 had liver transplant $[9,12,13,18], 2$ had heart transplant $[11,14]$, and 1 had bone marrow transplant [15]. The mean age of patients was $29.9 \pm 15.2$ years with no gender predominance ( 8 females and 7 males). None of the patients had history of diabetes mellitus prior to the transplant. $40 \%$ of patients, including our patient presented with DKA within the first 3 months after transplant, with median of 7 months.

Higher body mass index (BMI) has been associated with increased risk for NODAT [2]. However, lower BMI has been reported with tacrolimus-associated DKA in organ transplant patients, with mean of $22.1 \pm 4.7 \mathrm{~kg} / \mathrm{m}^{2}$ as in our case.

Female gender, African American ethnicity, recipients of deceased donor kidney transplant, younger age (33-44 versus $>55$ years), and recent transplant patients had significantly higher risk of DKA after kidney transplantation [19].
Maintenance immunosuppressive therapy is essential to prevent rejection in renal transplant recipients. Calcineurin inhibitors play an integral role in immunosuppressive regimens, with tacrolimus being the preferred agent over cyclosporine, as several studies showed lower incidence of acute rejections with its use $[4,20]$. In addition to lower rates of acute rejections, tacrolimus is better tolerated and preferred by patients compared with cyclosporine. Moreover, tacrolimus does not lower mycophenolate levels unlike cyclosporine and, therefore, relatively lower doses of mycophenolate are needed when tacrolimus is used.

Transplant patients on tacrolimus as part of their immunosuppressive regimen had increased risk of DKA compared to cyclosporine based immunosuppressive regimens [7, 19]. Both calcineurin inhibitors cause toxicity to pancreatic islet beta cells and may directly affect transcriptional regulation of insulin expression [21, 22]. Some evidence suggests however that tacrolimus causes more severe swelling-vacuolization, endoplasmic reticulum stress, and apoptosis of pancreatic islet beta cells [23]. Toxic levels of tacrolimus and higher steroid doses potentiate each other's diabetogenic effects [24]. Tacrolimus's diabetogenic effects therefore threaten the health and longevity of the allograft by predisposing the recipients to microvascular and macrovascular diabetes complications which consequently reduce allograft survival.

Decreased insulin requirement after DKA is suggestive of transient pancreatic damage by toxic levels of tacrolimus which is usually dose dependent and appears reversible [24]. Both tapering tacrolimus regimens and cyclosporine substitution for tacrolimus have been associated with decreased insulin requirements. There is one case report in which everolimus substitution for tacrolimus provided sufficient decline in insulin requirements [17].

Importantly, DKA in renal transplant patients has been associated with increased mortality [19].

\section{Conclusion}

Tacrolimus remains the preferred immunosuppressive agent after kidney transplantation given lower incidence of acute rejections and better patients' tolerance. However, tacrolimus's contribution to new-onset diabetes ketoacidosis, as a consequence of pancreatic islet beta cell toxicity, adds to the accumulating evidence of reduced allograft survival observed since its introduction as the immunosuppressant of choice. Despite rarity of reported cases of posttransplant tacrolimus-induced DKA, it seems possible that the decrease in allograft survival observed in the last two decades is just the consequence of tacrolimus-induced diabetes and its complications. The successful decrease in acute allograft rejection provided by tacrolimus has likely confounded this observation. The development of diabetes mellitus with ketoacidosis in patients on therapeutic tacrolimus levels, with no risk factors for diabetes, highlights the need for alternative immunosuppressive agents that will not compromise patients' allografts long-term survival at the expense of inducing a devastating chronic disease. This case 


\begin{tabular}{|c|c|c|c|c|c|c|c|c|c|}
\hline 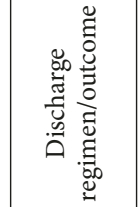 & 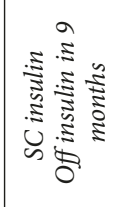 & 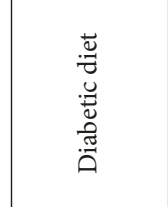 & 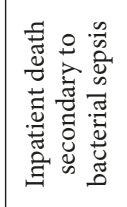 & 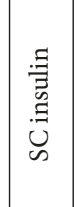 & 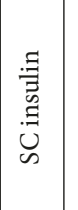 & 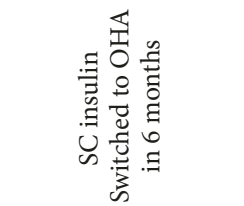 & 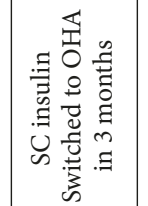 & $\begin{array}{l}\text { 寻 } \\
\text { 总 } \\
\text { 品 }\end{array}$ & 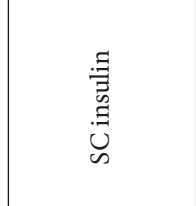 \\
\hline 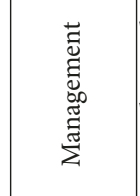 & 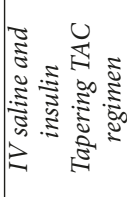 & 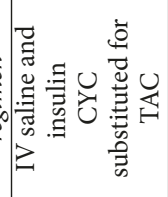 & 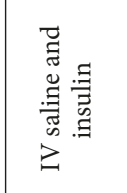 & 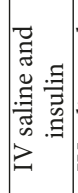 & 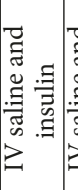 & 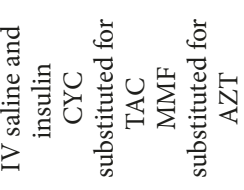 & 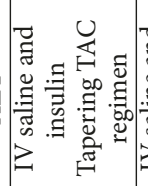 & 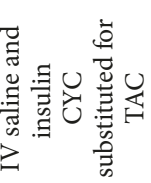 & 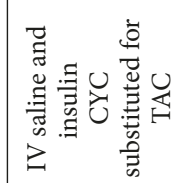 \\
\hline 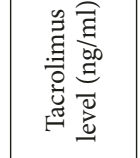 & छे & $\exists$ & $\stackrel{\overbrace{}}{0}$ & $\stackrel{\infty}{\stackrel{\infty}{ \pm}}$ & $\begin{array}{l}n \\
0 \\
0\end{array}$ & i & $\stackrel{\wedge}{\wedge}$ & 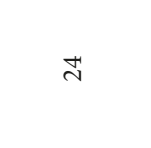 & $\overleftrightarrow{z}$ \\
\hline 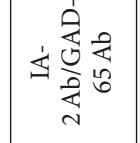 & $\frac{1}{z}$ & $\frac{1}{\frac{1}{z}}$ & 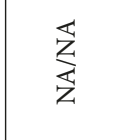 & 妾 & 娄 & 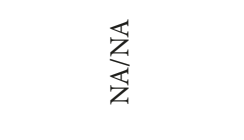 & 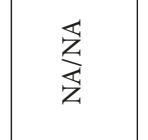 & 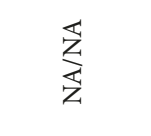 & $\frac{1}{1}$ \\
\hline 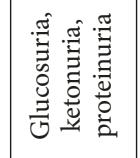 & $\frac{1}{+}$ & 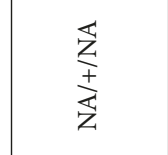 & 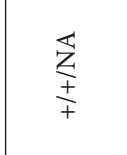 & $\frac{\underset{z}{z}}{+}$ & $\underset{\substack{z \\
z \\
z}}{\frac{1}{z}}$ & $\frac{+}{+}$ & $\frac{\underset{z}{z}}{+}$ & $\frac{t}{+}$ & 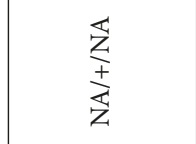 \\
\hline 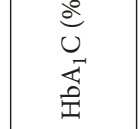 & $\stackrel{\infty}{\circ}$ & $\stackrel{\curvearrowright}{ \pm}$ & 㐏 & $\overleftrightarrow{z}$ & 艺 & $\stackrel{\circ}{=}$ & $\overrightarrow{\mathrm{I}}$ & $\stackrel{n}{=}$ & $\overleftrightarrow{z}$ \\
\hline 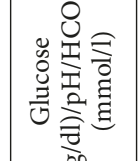 & 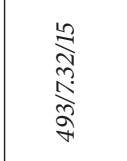 & 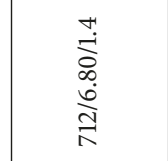 & 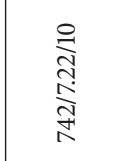 & 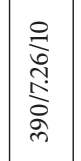 & 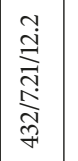 & 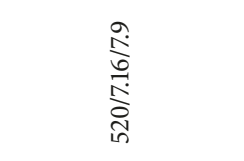 & 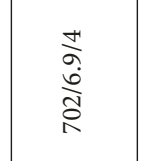 & 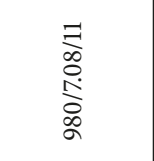 & 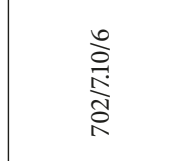 \\
\hline 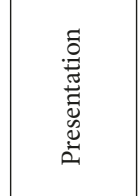 & 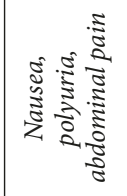 & 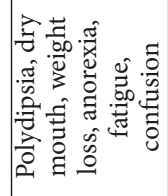 & 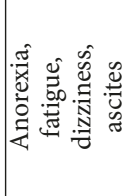 & 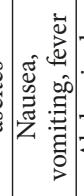 & 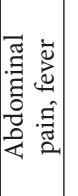 & 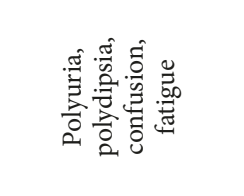 & 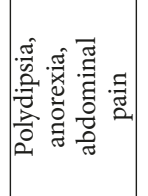 & 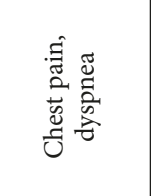 & 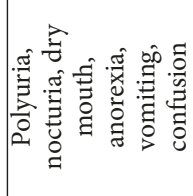 \\
\hline 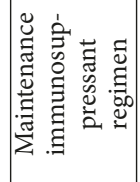 & 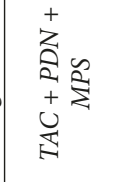 & 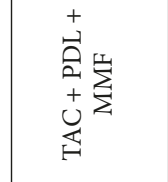 & 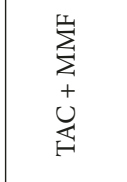 & 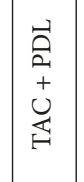 & $\begin{array}{l}\sum_{1} \\
\sum_{1} \\
+ \\
0 \\
\vec{H}\end{array}$ & 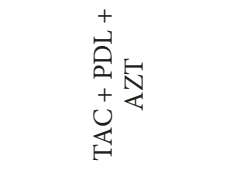 & $\underset{H}{U}$ & 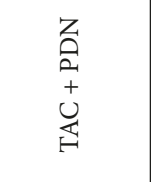 & 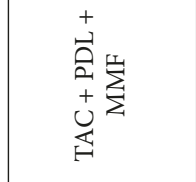 \\
\hline 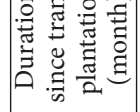 & $m$ & 0 & $\wedge$ & $n$ & $r$ & $\stackrel{m}{m}$ & $n$ & $\simeq$ & $\simeq$ \\
\hline 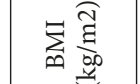 & 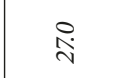 & $\stackrel{\infty}{\vec{\sim}}$ & $\overleftrightarrow{z}$ & $\overleftrightarrow{z}$ & $\overleftrightarrow{z}$ & ڤ̊. & 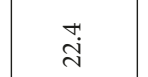 & $\overleftrightarrow{z}$ & $\overleftrightarrow{z}$ \\
\hline 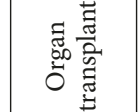 & है & 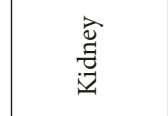 & 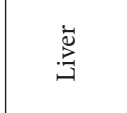 & 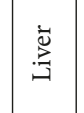 & $\stackrel{\vec{\nu}}{:}$ & 氙 & 壹 & 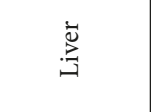 & 苛 \\
\hline 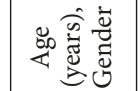 & $\underset{F}{F}$ & 空 & $\stackrel{4}{9}$ & $\sum_{\exists}$ & $\sum_{I}$ & 岁 & $\underset{\sim}{\sim}$ & $\underset{\exists}{\Psi}$ & $\sum_{\triangle}$ \\
\hline & $\begin{array}{l}\tilde{8} \\
\vdots \\
\vdots\end{array}$ & $\begin{array}{l}\text { 摛 } \\
0 \\
0 \\
0 \\
0\end{array}$ & 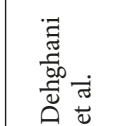 & 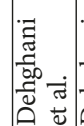 & $\mid$ & 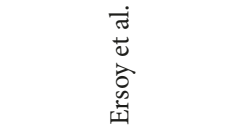 & 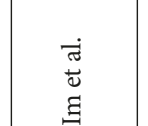 & 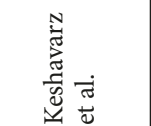 & 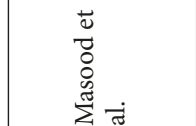 \\
\hline
\end{tabular}




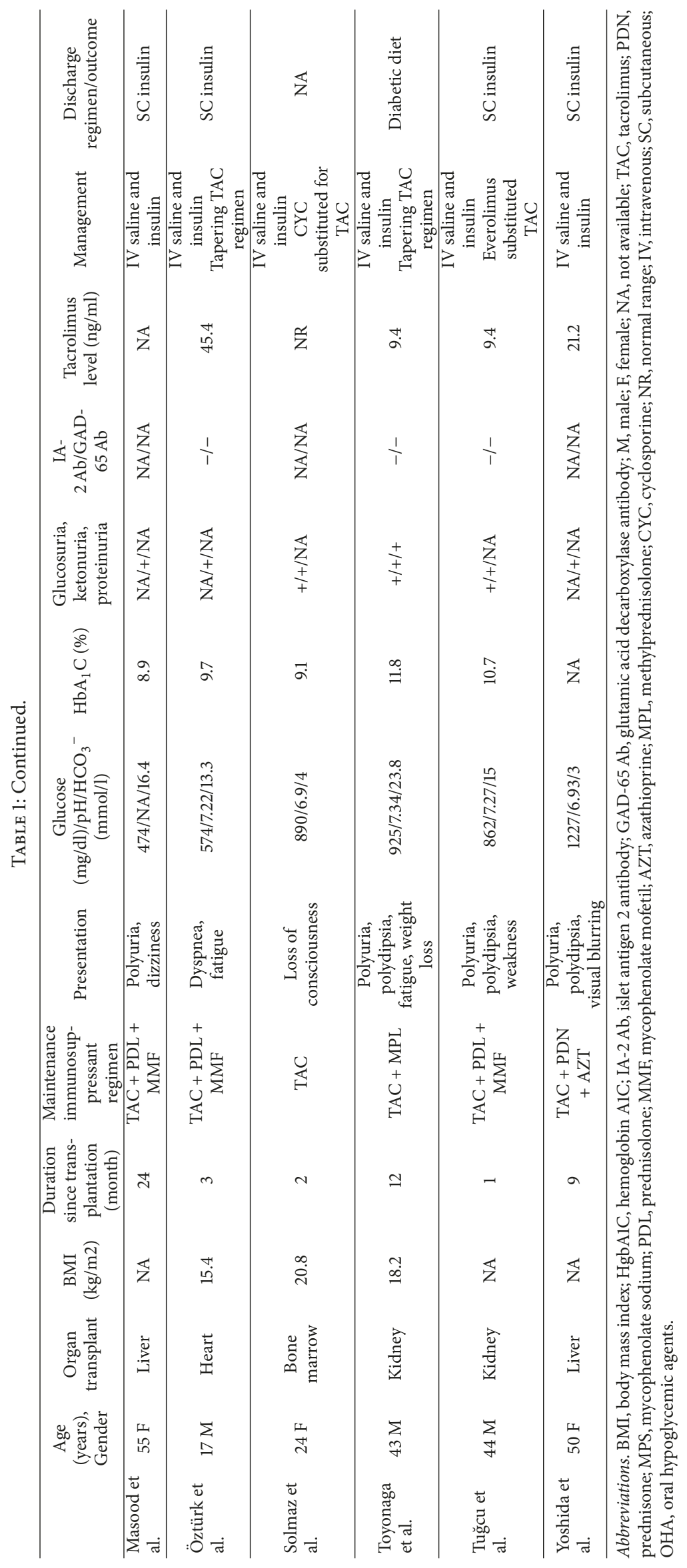


study highlights the importance of regular monitoring of fasting blood glucose in transplant patients on tacrolimus based regimen for early detection of NODAT in order to prevent life-threatening complications. It is also another call for attention on the toxic effects of this potent calcineurin inhibitor.

\section{Abbreviations}

DKA: Diabetic ketoacidosis

ADPKD: Autosomal dominant polycystic kidney disease NODAT: New-onset diabetes mellitus after transplantation ESRD: End stage renal disease.

\section{Conflicts of Interest}

The authors declare that they have no conflicts of interest.

\section{Authors' Contributions}

Zaid Ammari was responsible for conception and design of the article, data collection, data analysis and interpretation, drafting of the article, and final approval of the version to be published. Stella C. Pak, Mohammed Ruzieh, Osama Dasa, and Abhinav Tiwari were responsible for data collection, data analysis and interpretation, drafting of the article, and final approval of the version to be published. Juan C. Jaume and Maria A. Alfonso-Jaume were responsible for critical revision of the article and final approval of the version to be published.

\section{References}

[1] E. L. Porrini, J. M. Díaz, F. Moreso et al., "Clinical evolution of post-transplant diabetes mellitus," Nephrology Dialysis Transplantation, vol. 31, no. 3, pp. 495-505, 2016.

[2] Z. Kaposztas, E. Gyurus, and B. D. Kahan, "New-onset diabetes after renal transplantation: Diagnosis, incidence, risk factors, impact on outcomes, and novel implications," Transplantation Proceedings, vol. 43, no. 5, pp. 1375-1394, 2011.

[3] O. Heisel, R. Heisel, R. Balshaw, and P. Keown, "New Onset Diabetes Mellitus in Patients Receiving Calcineurin Inhibitors: A Systematic Review and Meta-Analysis," American Journal of Transplantation, vol. 4, no. 4, pp. 583-595, 2004.

[4] F. Vincenti, S. Friman, E. Scheuermann et al., "Results of an international, randomized trial comparing glucose metabolism disorders and outcome with cyclosporine versus tacrolimus," Am J Transplant, vol. 7, no. 6, pp. 1506-1514, 2007.

[5] J. W. Huang, O. Famure, Y. Li, and S. J. Kim, "Hypomagnesemia and the Risk of New-Onset Diabetes Mellitus after Kidney Transplantation," J Am Soc Nephrol, vol. 27, no. 6, pp. 1793-1800, 2016.

[6] R. A. Hamer, C. L. Chow, A. C. M. Ong, and W. S. McKane, "Polycystic kidney disease is a risk factor for new-onset diabetes after transplantation," Transplantation, vol. 83, no. 1, pp. 36-40, 2007.

[7] T. E. Burroughs, J. Swindle, S. Takemoto et al., "Diabetic complications associated with new-onset diabetes mellitus in renal transplant recipients," Transplantation, vol. 83, no. 8, pp. 1027-1034, 2007.
[8] Y. M. Cho, K. S. Park, H. S. Jung, Y. S. Kim, S. Y. Kim, and H. K. Lee, "A case showing complete insulin independence after severe diabetic ketoacidosis associated with tacrolimus treatment.," Diabetes Care, vol. 25, no. 9, p. 1664, 2002.

[9] S. M. Dehghani, S. Nikeghbalian, A. Eshraghian et al., "Newonset diabetes mellitus presenting with diabetic ketoacidosis after pediatric liver transplantation," Pediatric Transplantation, vol. 13, no. 5, pp. 536-539, 2009.

[10] A. Ersoy, C. Ersoy, H. Tekce, I. Yavascaoglu, and K. Dilek, "Diabetic ketoacidosis following development of de novo diabetes in renal transplant recipient associated with tacrolimus," Transplantation Proceedings, vol. 36, no. 5, pp. 1407-1410, 2004.

[11] M.-S. Im, H.-S. Ahn, H.-J. Cho, K.-B. Kim, and H.-Y. Lee, "Diabetic ketoacidosis associated with acute pancreatitis in a heart transplant recipient treated with tacrolimus," Experimental and Clinical Transplantation, vol. 11, no. 1, pp. 72-74, 2013.

[12] R. Keshavarz, M.-A. Mousavi, and C. Hassani, "Diabetic ketoacidosis in a child on FK506 immunosuppression after a liver transplant," Pediatric Emergency Care, vol. 18, no. 1, pp. 2224, 2002.

[13] M. Q. Masood, M. Rabbani, W. Jafri, M. Habib, and T. Saleem, "Diabetic ketoacidosis associated with tacrolimus in solid organ transplant recipients," Journal of the Pakistan Medical Association, vol. 61, no. 3, pp. 288-290, 2011.

[14] Z. Öztürk, E. Nazlı Gönç, L. Akcan, S. Kesici, İ. Ertuğrul, and B. Bayrakçı, "A rare but important adverse effect of tacrolimus in a heart transplant recipient: Diabetic ketoacidosis," The Turkish Journal of Pediatrics, vol. 57, no. 5, pp. 533-535, 2015.

[15] S. Solmaz, Z. Gokgoz, and C. Gereklioglu, "Tacrolimus-Induced Diabetic Ketoacidosis After Allogeneic Bone Marrow Transplant," Exp Clin Transplant, 2015.

[16] T. Toyonaga, T. Kondo, N. Miyamura et al., "Sudden onset of diabetes with ketoacidosis in a patient treated with FK506/ tacrolimus," Diabetes Research and Clinical Practice, vol. 56, no. 1, pp. 13-18, 2002.

[17] M. Tuğcu, U. Kasapoglu, B. Boynuegri et al., "Tacrolimusinduced diabetic ketoacidosis and effect of switching to everolimus: a case report," Transplantation Proceedings, vol. 47, no. 5, pp. 1528-1530, 2015.

[18] E. M. Yoshida, A. K. Buczkowski, S. M. Sirrs et al., "Posttransplant diabetic ketoacidosis - A possible consequence of immunosuppression with calcineurin inhibiting agents: A case series," Transplant International, vol. 13, no. 1, pp. 69-72, 2000.

[19] K. C. Abbott, V. J. Bernet, L. Y. Agodoa, and C. M. Yuan, "Diabetic ketoacidosis and hyperglycemic hyperosmolar syndrome after renal tranplantation in the United States," BMC Endocrine Disorders, vol. 3, article no. 1, 2003.

[20] M. Kamel, M. Kadian, T. Srinivas, D. Taber, and M. A. Salas, "Tacrolimus confers lower acute rejection rates and better renal allograft survival compared to cyclosporine," World Journal of Transplantation, vol. 6, no. 4, p. 697, 2016.

[21] L. A. Øzbay, K. Smidt, D. M. Mortensen, J. Carstens, K. A. Jørgensen, and J. Rungby, "Cyclosporin and tacrolimus impair insulin secretion and transcriptional regulation in INS-1E betacells," British Journal of Pharmacology, vol. 162, no. 1, pp. 136146, 2011.

[22] I. Hernández-Fisac, J. Pizarro-Delgado, C. Calle et al., "Tacrolimus-induced diabetes in rats courses with suppressed insulin gene expression in pancreatic islets," American Journal of Transplantation, vol. 7, no. 11, pp. 2455-2462, 2007. 
[23] E. B. Rangel, "Tacrolimus in pancreas transplant: A focus on toxicity, diabetogenic effect and drug-drug interactions," Expert Opinion on Drug Metabolism \& Toxicology, vol. 10, no. 11, pp. 1585-1605, 2014.

[24] C. B. Drachenberg, D. K. Klassen, M. R. Weir et al., "Islet cell damage associated with tacrolimus and cyclosporine: Morphological features in pancreas allograft biopsies and clinical correlation," Transplantation, vol. 68, no. 3, pp. 396-402, 1999. 


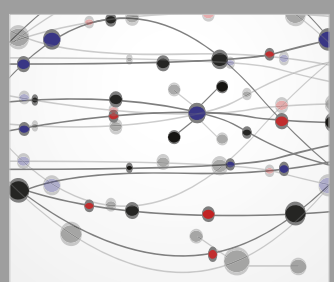

The Scientific World Journal
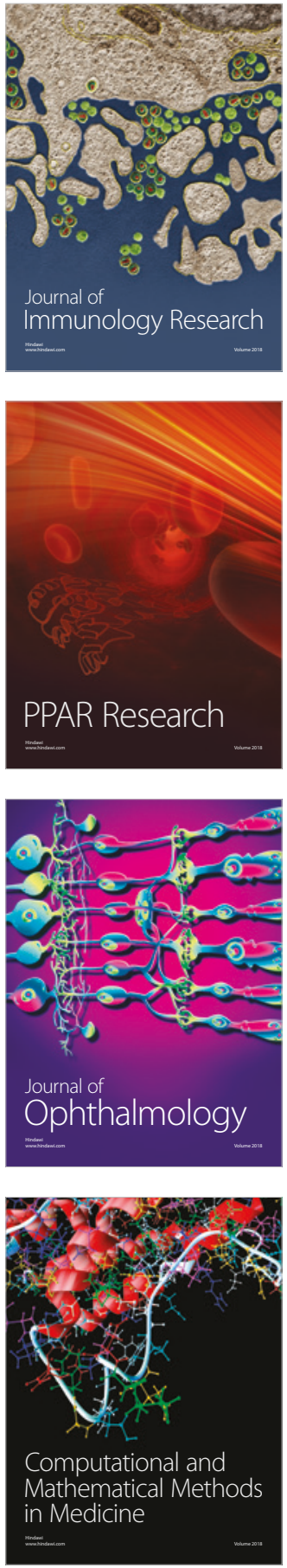

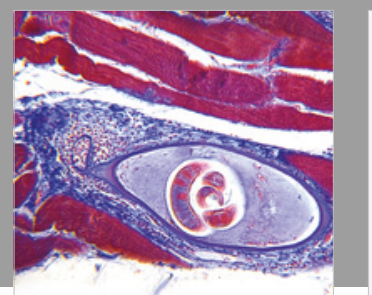

Gastroenterology Research and Practice

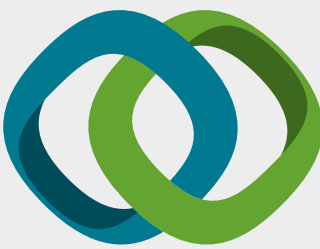

\section{Hindawi}

Submit your manuscripts at

www.hindawi.com
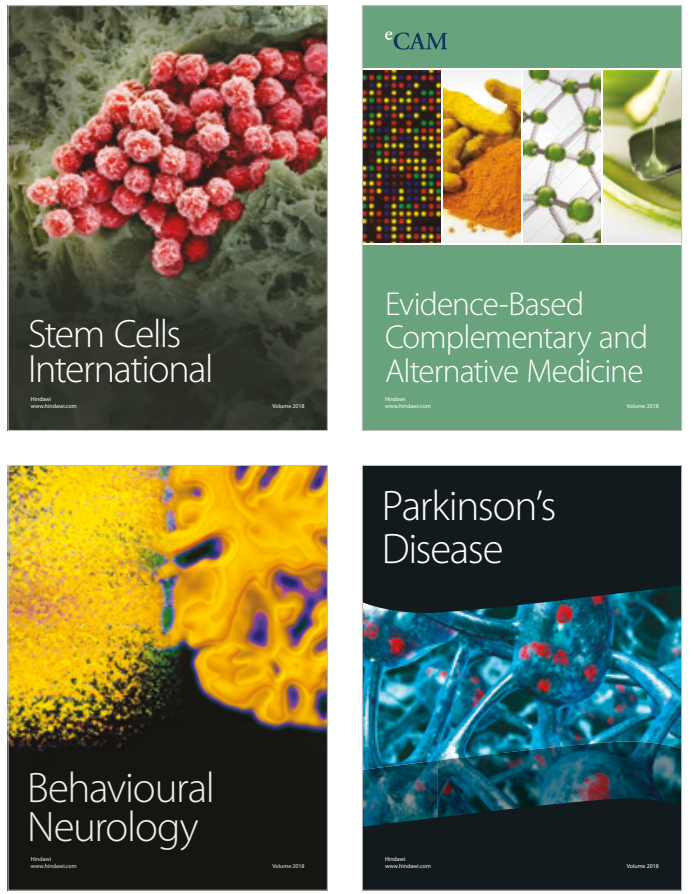

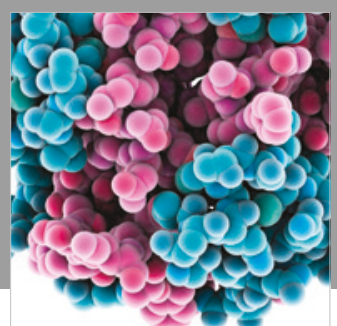

ournal of

Diabetes Research

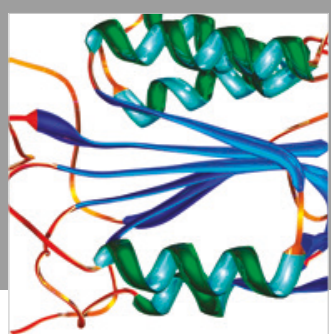

Disease Markers
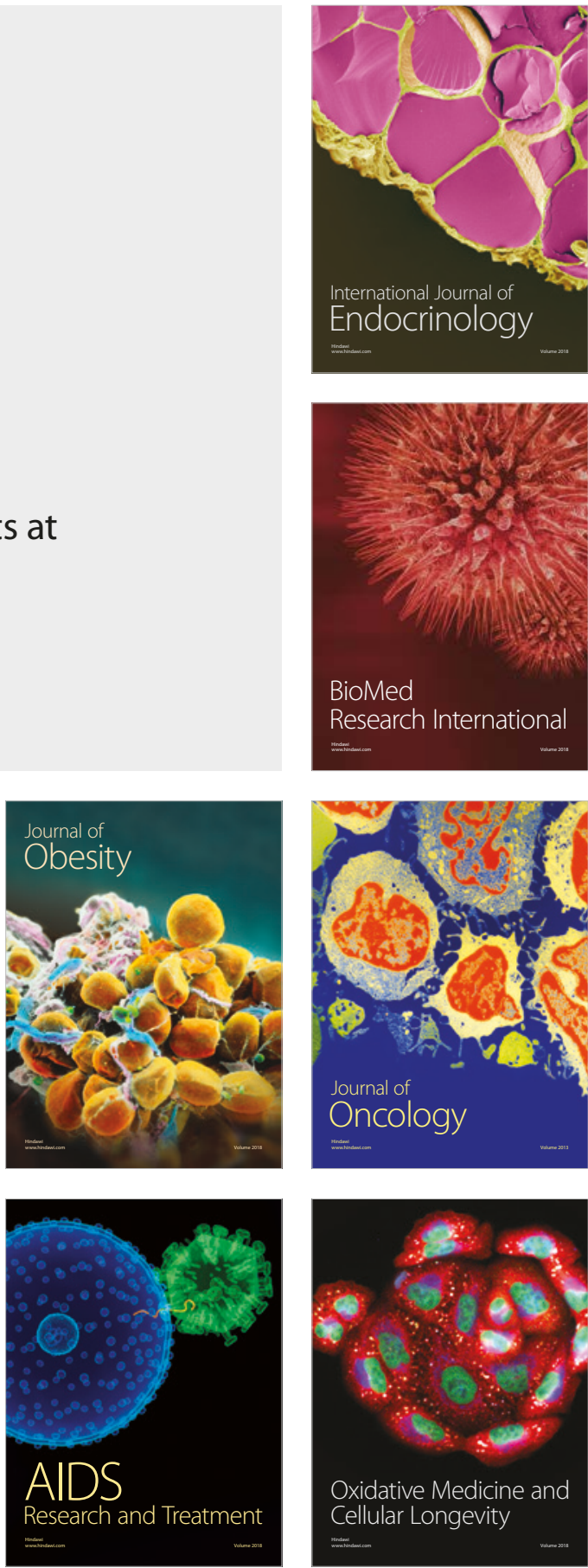